УДК 069.231.3

DOI: $10.15587 / 2313-8416.2014 .28465$

\title{
ТЕРМИЧЕСКОЕ РАЗЛОЖЕНИЕ И ОКИСЛЕНИЕ ХЛОРИДА ТИТАНА В РАСПЛАВАХ ХЛОРИДОВ НАТРИЯ И КАЛИЯ, СТРУКТУРА ОБРАЗУЮЩЕГОСЯ ДИОКСИДА ТИТАНА
}

\author{
(C) В. П. Шапорев, А. В. Шестопалов, И. В. Питак
}

В статье представлень экспериментальные и теоретические результаты практического получения нитевидных кристаллов $\mathrm{TiO}_{2}$ путем окисления $\mathrm{TiCl}_{4}$ кислородом воздуха в расплаве солей $\mathrm{NaCl}$, $\mathrm{KCl}$. Рассчитанные кинетические параметры позволяют организовать процесс с заданной скоростью протекания и необходимым выходом продукта. Приведенные результаты позволяют осознанно подойти к разработке усовершенствованного реактора для производства нитевидных кристаллов $\mathrm{TiO}_{2}$.

Ключевые слова: нитевидные кристалль, оксид титана, кинетические параметры, кристаллизация, расплав солей.

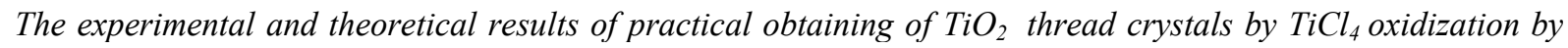
air oxygen in fusion of $\mathrm{NaCl}$ and $\mathrm{KCl}$ salts are represented in the article. The calculated kinetic parameters allow to organize a process with the set speed of flowing and necessary of product output. The results allow realized the development of the improved reactor for $\mathrm{TiO}_{2}$ thread crystals production.

Keywords: thread crystals, titanium oxide, kinetic parameters, crystallization, fusion of salts.

\section{1. Введение}

Сегодня получение нитевидных кристаллов $\mathrm{TiO}_{2}$, представляющих интерес в различных сферах промышленности, в процессе газово-фазовой химической реакции становится весьма актуальной и перспективной задачей, потому что данная технология позволяет выгодно управлять условиями, размерами частиц, кристаллической структурой и чистотой выходящего продукта.

Взаимодействие хлорида титана $\left(\mathrm{TiCl}_{4}\right)$ с кислородом воздуха может осуществляться в паровой фазе при температуре 1073-1173 К [1]. В соответствии с результатами исследований [1] синтезированные частицы $\mathrm{TiO}_{2}$ в характеризуются сферической формой и размерами от 0,03 до 0,10 мкм. Паказано, что парциальное давление исходного $\mathrm{TiCl}_{4}$ в отличие от температуры процесса и его скорости не оказывает существенного влияния на размер и форму частиц $\mathrm{TiO}_{2}$. Исходя из расчетов распределения частиц $\mathrm{TiO}_{2}$ по размерам, выполненных в работе [1], с использованием Броуновской медели коагуляции применительно к системам с параллельными процессами, сделан вывод о доминирующей роли коагуляции в ходе роста частиц.

\section{2. Постановка проблемы}

В работах [2, 3] установлена возможность получения оксида титана с различной структурой путем взаимодействия $\mathrm{TiCl}_{4}, \mathrm{TiB}_{4}, \mathrm{TiJ}_{4}$ или их смесейс кислородом (чистым или кислородом воздуха) в присутствии галоидов металлов.

В работе [3] показано, что лучшие результаты по выходу $\mathrm{TiO}_{2}$ достигаются при использовании $\mathrm{TiCl}_{4}$ и расплава смеси солей $\mathrm{NaCl}$ и $\mathrm{KCl}$ при соотношении $\mathrm{NaCl} / \mathrm{KCl}=1,5$ и температуре расплава 973-1173 К, если используется избыток кислорода по отношению к $\mathrm{TiCl}_{4}$ в пределах 1,2-2,5.
В работах [2, 3] было показано, что структура $\mathrm{TiO}_{2}$, образующаяся в расплаве солей $\mathrm{NaCl} / \mathrm{KCl}$ после кристаллизации может иметь форму от нитевидных сферических частиц до нитевидных кристаллов (волокон). Последние после обработки волокон $\mathrm{TiO}_{2}$ слабым раствором $\mathrm{HCl}$ и водой, последующей фильтрацией образовывают маты и плотные диафрагмы, которые используются по назначению.

Преимущество этого метода получения $\mathrm{TiO}_{2}$ заключается в том, что процесс может быть осуществлен при атмосферном давлении при продувке газообразной смеси $\mathrm{TiCl}_{4}+$ воздух над слоем расплава солей $\mathrm{NaCl}$ и $\mathrm{KCl}$.

$\mathrm{C}$ этой точки зрения процесс получения $\mathrm{TiO}_{2} \mathrm{c}$ различной структурой является управляемым и относительно безопасным. Так, например, как указывается в [4], увеличение температуры с 900 до $1100{ }^{\circ} \mathrm{C}$ и сокращение времени пребывания реагентов в реакционной зоне позволяет уменьшить средний размер синтезированных кристаллов. Однако, результаты приведенные в работах [1-4] не позволяют достоверно определить механизм процесса образования $\mathrm{TiO}_{2}$, кинетические параметры, а также механизм и кинетику роста волокнистых кристаллов.

Предлагаемая статья посвящена изучению вышеуказанных вопросов при реализации процесса над расплавом солей $\mathrm{NaCl}, \mathrm{KCl}$ при температурах $1000-1200 \mathrm{~K}$.

\section{3. Литературный обзор}

Синтез волокнистого диоксида титана окислением а газовой фазе $\mathrm{TiCl}_{4}$ изучался многими исследователями [1-8], которые изучали закономерности процесса и различные параметры получения $\mathrm{TiO}_{2}, \quad$ (температуру, концентрации реагентов, парциальное давление, время пребывания реагентов в реакционной зоне и т. д.). Согласно этих 
работ реакция термического разложения $\mathrm{TiCl}_{4}$ в общем случае можно представить следующим уравнением:

$$
\mathrm{TiCl}_{4}+\mathrm{O}_{2}=\mathrm{TiO}_{2}+2 \mathrm{Cl}_{2}
$$

Причем реакция протекает в расплаве солей $\mathrm{NaCl}, \mathrm{KCl}$ и $\mathrm{TiO}_{2}$, который остается в растворе, а образовавшийся $\mathrm{Cl}_{2}$ диффундирует из расплава и отводится из зоны реакции вместе с выходящим газовым потоком. Таким образом, согласно [2, 3], в раствор-расплаве накапливается $\mathrm{TiO}_{2 \mathrm{p}}$, а затем по достижению пересыщения в системе по $\mathrm{TiO}_{2}$ идет кристаллизация с образованием различных форм кристаллов, то есть фактически по уравнению:

$$
\mathrm{TiO}_{2 \mathrm{p}} \rightarrow \mathrm{TiO}_{2} \text { тв. кр. }
$$

Реакция (1) является равновесной и достичь полного разложения $\mathrm{TiCl}_{4}$ можно путем удаления $\mathrm{Cl}_{2}$ из зоны реакции, что обеспечивается продуванием над расплавом потока газа. Реакция (2) может начаться только при достижении расплавом некоторого пересыщения по $\mathrm{TiO}_{2 \mathrm{p}}$. При выбранных температурных параметрах исследования процесса (1100-1200 К), при возможной навески шихты $(\mathrm{NaCl}$, $\mathrm{KCl})$ в каждой лодочке 300-500 г в расплаве может раствориться 25-40 Г $\quad \mathrm{TiO}_{2}$ и образуется пересыщенный раствор по $\mathrm{TiO}_{2}$. Таким образом, период начала реакции (2) полностью зависит от скорости реакции (1). Реакция (1) является реакцией первого порядка, согласно [1] значение порядка реакции $\sim 0,95$ и энергия активации 39 ккал/моль.

\section{дований \\ 4. Методика экспериментальных иссле-}

Принципиальная схема экспериментальной установки длия проведения реакции получения нитевидных кристаллов оксида титана приведена на рис. 1. Печь, приведенная на рис. 1. разработана ОКБ Таганрогского завода «Электрического оборудования». Основные показатели технической характеристики печи ОКБ - 8066 следующие:

- максимальная температура в рабочей камеpe $-1623 \mathrm{~K}$;

- рабочая среда - воздух, воздух - хлор;

- равномерное распределение температуры в рабочем пространчтве - 2 градуса;

- точность воспроизводимости уровня температуры в рабочем пространстве - \pm 2 градуса;

- потребляемая мощность - 20 кВт.

При проведении опытов загруженные шихтой (смесь $\mathrm{NaCl}+\mathrm{KCl}$ ), лодочки в виде пакета из 4-6 лодочек устанавливали в загрузочную зону печи (на схеме не показана) и продвигали толкателем поз. 8 в реакционную зону, имеющую температуру (1000-3000) \pm 25 K (термопара 91). В этой зоне происходит плавление шихты, после расплавления которой камера печи через поз. 4 и 5 продувается чистым азотом, который подается из баллонов. При этом предварительно перед вводом в печь азот пропускается через ловушку, заполненную слоем гранул силикагеля для очистки от возможных примесей и молекул воды. После продувки азотом в течение 10-15 минут поток азота заменяется на поток газа, состоящего из смеси $\mathrm{TiCl}_{4}+$ воздух. Указанная смесь газов (поток) получался следующим образом. Воздух, отвечающий требованиям КИП (допустимое количество примесей и ПДК) подавался компрессором через ловушки, заполненные слоем гранул силикагеля и пятиоксида фосфора, а затем вниз барботажной колонны, заполненной жидким $\mathrm{TiCl}_{4}$.

Колонна имела высоту 120 см, диаметр 12 см, сепарационная часть колонны состояла по высоте 30 см. Перед подачей в колонну осушенный воздух при необходимости подогревался до необходимой температуры (максимальная 420 K).

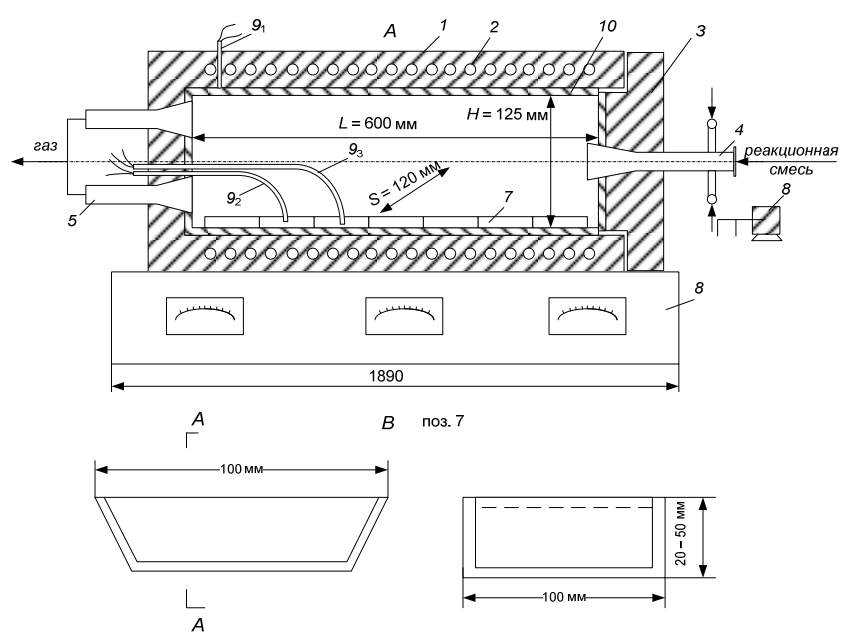

Рис. 1. Печь для экспериментальных исследований:

1 - кожух печи; 2 - нагреватели - силитовые стержни; 3 - передняя дверь печи; 4 - устройство для подачи реакционного газа; 5 - устройство для отвода газов; 6 - приборный щит управления; 7 - лодочки с плавом $\mathrm{NaCl}, \mathrm{KCl}$ из плавленого прозрачного кварца; 8 - устройство-толкатель для подачи лодочек в печь

и вывода лодочки из горячей печи; 9 - платино-

родиевые термопары; 10 - корундовый высокоогнеупорный тюфель

Полученная на выходе из колонные газовая смесь подавалась в ресивер, оттуда дозировалась ротаметром в камеру печи. Расход смеси дозировался ротаметром в пределах от 15 до $150 \mathrm{~cm}^{3} /$ мин. Время проведения процесса в лодочках изменялась от 120 до 1520 мин. Выходящие из печи газы поступали в абсорбер с раствором $\mathrm{NaOH}$. Для снятия кинетики образования и роста кристаллов $\mathrm{TiO}_{2}$ периодически через определенные промежутки времени кратковременно на период 2-3 минуты прекращалась подача реакционной смеси, открывались передняя дверь печи (поз. 3) и устройством-толктелем (поз. 8) извлекалась та или иная лодочка на загрузочный стол (зону) печи. Лодочка охлаждалась и переносилась в выщелачиватель, где находислась смесь этилового спирта с дистиллированной водой $(1: 1)$.

Характеристики реагентов, использовались в исследованиях: 
- NaCl-M=58,44, $\rho=2,165 \quad \Gamma / \mathrm{cm}^{3}, \mathrm{~T}_{\text {пл }}=1074 \mathrm{~K}$, $\mathrm{C}_{\mathrm{p}}=49,71$ Дж· моль $^{-1} \cdot \mathrm{K}^{-1}$;

- KCl-M=74,55, $\rho=1,93 \quad \Gamma / \mathrm{cm}^{3}, \quad \mathrm{~T}_{\mathrm{nI}}=1049 \mathrm{~K}$, $\mathrm{C}_{\mathrm{p}}=51,29$ Дж $\cdot$ моль $^{-1} \cdot \mathrm{K}^{-1}$;

- $\mathrm{TiCl}_{4}-\mathrm{M}=189,7, \rho=1,728 \quad \Gamma / \mathrm{cm}^{3}, \mathrm{~T}_{\text {пл }}=249 \mathrm{~K}$, $\mathrm{T}_{\text {кип }}=409,5 \quad \mathrm{~K}, \quad \mathrm{C}_{\mathrm{p}}=145,2 \quad$ Дж. моль ${ }^{-1} \cdot \mathrm{K}^{-1}$, $\Delta \mathrm{H}_{\text {исп }}=35,7$ кДж $\cdot$ моль $^{-1}$.

Смесь солей $\mathrm{NaCl}, \mathrm{KCl}$ в соотношении 1,5 при 1000 К представляет собой жидкую массу. Продукты реакции в извлеченных и охлажденных лодочках подвергались рентгенофазовому анализу с помощью дифектометра ДРОН - 2 в $\mathrm{Cu}_{\alpha}-$ излучении при напряжении в трубке 36 кВ и силе тока 10 мА. Монохроматором служил графит, что обеспечивало хорошее разрешение линий на дифрактограммах. Дифракционные картины анализировали по интенсивности основных линий, характерных для $\mathrm{TiO}_{2}$ (по ASTM) - I=100 \%, d=3,25 $\AA$ [110]; $\mathrm{I}=63 \%$, $\mathrm{d}=1,689 \AA$ [211]; $\mathrm{I}=30 \%, \mathrm{~d}=2,188 \AA$ [200], с целью не только обнаружения $\mathrm{TiO}_{2}$ той или иной модификации, но и с целью оценки количества образовавшегося продукте по методикам, изложенным в $[9,10]$.

Кроме того, для исследований использовался весовой метод, когда скорость образования $\mathrm{TiO}_{2}$ контролировалась по увеличению массы исходного расплава $\mathrm{NaCl}, \mathrm{KCl}$.

Замеры образовавшихся частиц $\mathrm{TiO}_{2}$ и определяющие структуры после обработки охлажденного плава спиртово-водной средой проводили на электронном микроскопе УЭВМ - 100 и просвечивающем электронном микроскопе фирмы
Siemens «Эльмископ - 1». Морфологию кристаллов изучали с помощью сканирующего электронного микроскопа JSM - 2 (Япония). Электропроводность получаемых кристаллов, их теплопроводность, пластические свойства определяли по методикам, описанным в работе [11].

\section{5. Результаты экспериментальных \\ исследований}

Вначале оценим результаты качественных экспериментов при реализации процесса в целом. Наблюдения за ростом кристаллов $\mathrm{TiO}_{2}$ (рис. 2) показали, что в выбранном интервале температур (1100-1300 К) расплава $\mathrm{NaCl}, \mathrm{KCl}$ при продувании над расплавом смеси $\mathrm{TiCl}_{4}+$ воздух всегда через определенные промежутки времени $\tau$ наблюдались следующие явления:

- через определенный период $\tau_{1}$ расплав насыщается $\mathrm{TiO}_{2 p}$ с образованием пороговых включений, движение которых в дальнейшем обеспечивало рост кристалла (рис. $2, a$ );

- через определенный промежуток времени $\tau_{2}$ (отсчет от $\tau_{1}$ ) на поверхности расплава $\mathrm{NaCl}, \mathrm{KCl}$ образовывалась тонкая корка ( $\max 4$ мм), состоящая из волокон $\mathrm{TiO}_{2}$, расположенных в основном перпендикулярно поверхности расплава (рис. 2, б); после образования корки рост кристаллов прекращался;

- в промежутке времени $\tau_{3} \quad\left(\tau_{1}<\tau_{3}<\tau_{2}\right)$ наблюдался ассиметричный рост кристаллов $\mathrm{TiO}_{2}$ (рис. 2, в).

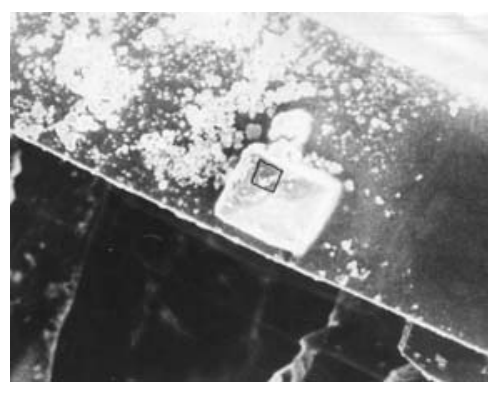

$a$

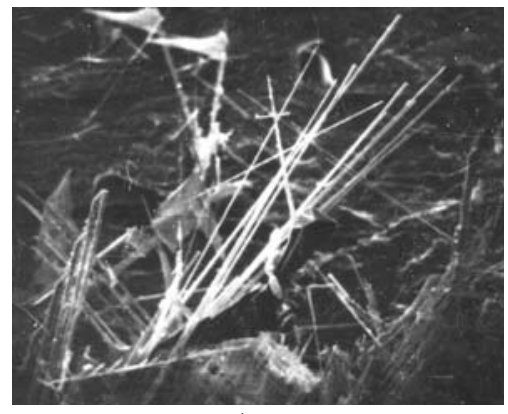

6

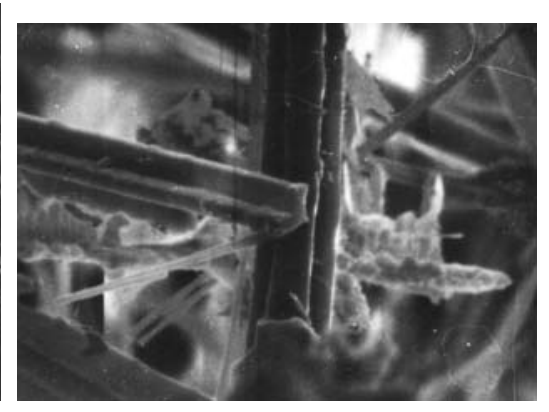

B

Рис. 2. Рост кристаллов $\mathrm{TiO}_{2}: a$ - образование пороговых включений (увеличение в 1000 раз); $\sigma$ - образование тонкой корки из волокон кристаллов (увеличение в 500 раз); в - ассиметричный рост кристаллов (увеличение в 1000 раз)

Факторы, влияющие на $\tau_{1}$, следующие: температура воздуха $T_{\text {в}}$, подаваемого в колонну с жидким $\mathrm{TiCl}_{4}$; скорость продувки $V_{m}$ газовой смеси $\left(\mathrm{TiCl}_{4}+\right.$ воздух) над расплавом $\mathrm{NaCl}, \mathrm{KCl}$; толщина расплава в лодочке, то есть величина $h$. На рис. 3-5 приведено влияние указанных параметров на $\tau_{1}$.

Из анализа экспериментальных данных, приведенных на рис. 3-5, результатов качественных экспериментов можно сделать вывод, что скорость химической реакции (1), то есть $\tau_{1}$ весьма слабо зависит от температуры расплава в исследуемом интервале $T_{\mathrm{p}}$ и весьма существенно зависит от скорости газового потока $V_{m}$, концентрации реагирующих веществ над поверхностью расплава $C$ (то есть при заданом $V_{m}$ от $T_{\text {в }}$ ), концентрации $C^{1}$ (концентрация реагентов в поверхностном слое расплава).

На рис. 5 приведена зависимость количества образовавшегося $\mathrm{TiO}_{2}$ в объеме расплава при

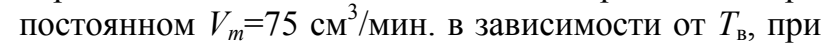
исходной толщине расплава $h=10$ мм и первоначальной массе 250 г $(\mathrm{NaCl}+\mathrm{KCl})$. 


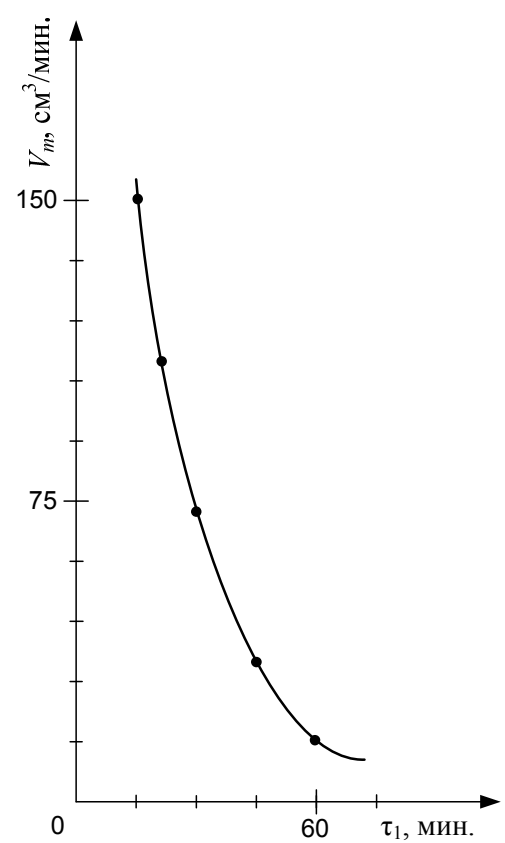

Рис. 3. Взаимосвязь величин $\tau_{1}$ и $V_{m}$ при $h=30 \mathrm{MM}, T_{\mathrm{B}}=420 \mathrm{~K}$

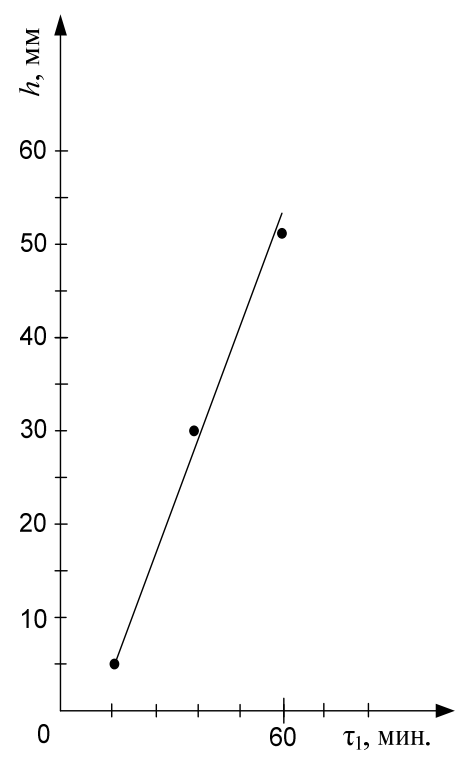

Рис. 4. Взаимосвязь величин $\tau_{1}$ и $h$ при $V_{m}=100 \mathrm{~cm}^{3} /$ мин., $T_{\mathrm{B}}=420 \mathrm{~K}$

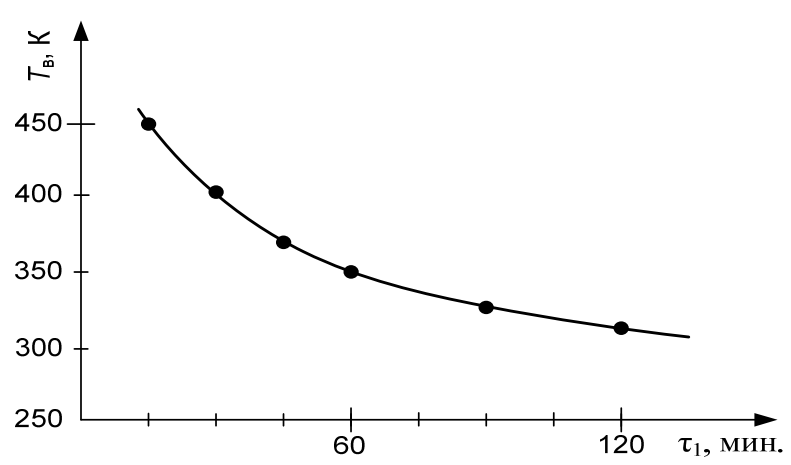

Рис. 5. Влияние $T_{\text {в }}$ на величину $\tau_{1}$ при $h=5$ мм, $V_{m}=75 \mathrm{~cm}^{3} / \mathrm{Mин}$
Рассматривая реагирующую систему (печь, лодочки, подача газа) можно считать, что это приближается к одному из простейших случаев внешней задачи, а именно передачи вещества между потоком газа и конденсированной фазой продольные обтекаемые пластины [12]. При этом, как следует из оценки «пластину» из расплава $\mathrm{NaCl}$, $\mathrm{KCl}$ толщиной от 5 до 40 мм омывает ламинарный газовый поток реакционной смеси. Критерий Рейнольдса Re газового потока в пространстве над расплавом не превышает значений $\approx 600$.

\section{6. Апробация результатов исследований}

Все вышеотмеченное свидетельствует о том, что в исследуемых условиях образования $\mathrm{TiO}_{2 \mathrm{p}}$ в расплаве $\mathrm{NaCl}, \mathrm{KCl}$ подчиняется диффузионной кинетике. Используя метод равнодоступной поверхности [13] уравнение для скорости образования $\mathrm{TiO}_{2 \mathrm{p}}$ в расплаве $\mathrm{NaCl}, \mathrm{KCl}$, если пренебречь внутридиффузионным торможением, то есть считать, что в период $\tau_{1}$ скорость отвода $\mathrm{Cl}_{2}$ из зоны реакции достаточно большая и не влияет на процесс $\left(\mathrm{Cl}_{2}\right.$ уносится с газовым потоком из печи), можно записать в виде:

$$
W=\beta C S,
$$

где $C-$ средняя концентрация реагентов над расплавом по объему печи; $S$ - геометрическая поверхность расплава; D - коэффициент диффузии газообразной смеси; $\beta$ - коэффициент массоотдачи от газового потока к расплаву.

По аналоги с Боресковым [14] уравнение (3) можно представить как:

$$
W=\frac{D \operatorname{Re}^{0,7} \operatorname{Pr}^{0,3} C S}{2,32 L} .
$$

Здесь $L$ - приведенный размер поверхности расплава, равный учетверенному отношения объема расплава к величине поверхности. Соответственно величина $\beta$ буде травна:

$$
\beta=\frac{D \operatorname{Re}^{0,7} \operatorname{Pr}^{0,3}}{2,32 L} .
$$

В дальнейших рассуждениях можно принять, что с поверхности расплава идет одномерная диффузия через элементарную толщину расплава h, a на противоположной стороне толщины идет химическая реакция.

Это допущение справедливо, поскольку кристаллизация $\mathrm{TiO}_{2}$, идет в объеме расплава, а так же на рис. 4 приведено влияние толщины слоя расплава $h$ на процесс. Тогда можно показать, что

$$
D \frac{d C}{d h}=k f\left(C^{\prime}\right) \text {, }
$$

где $k$ - константа скорости химической реакции.

Выражая градиент концентрации как

$$
\frac{d C}{d h}=\frac{\left(C-C^{\prime}\right)}{h}
$$

и учитывая, что $D / h=\beta$, найдем

$$
\beta\left(C-C^{\prime}\right)=k f\left(C^{\prime}\right) .
$$




$$
C^{\prime}=\frac{\beta}{\beta+k} C,
$$

а скорость реакции

$$
W=k^{*} C=\frac{k \beta}{k+\beta} C .
$$

При $k<<\beta$ можно пренебречь величиной $k$ в знаменателе и уравнение превращается в обычное уравнение первого порядка. Предельный случай $k>>$ $\beta, k^{*} \cong \beta, C^{\prime}=\frac{\beta}{k} C \leq C, W-$ определяется скоростью диффузии.

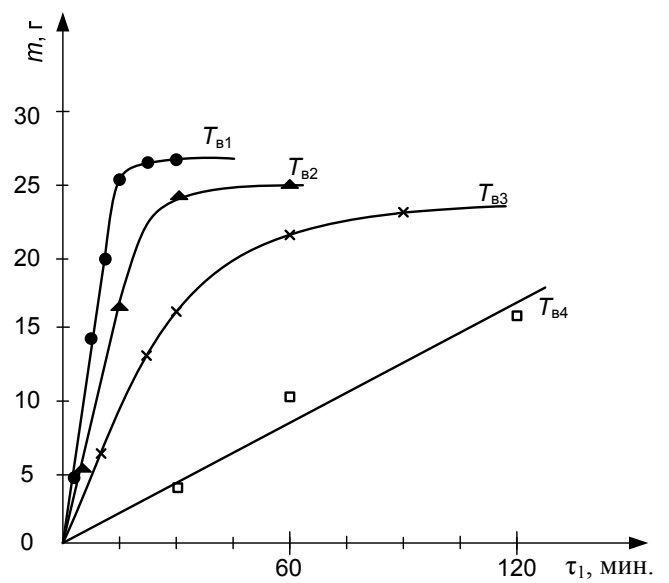

Рис. 6. Зависимость скорости образования $\mathrm{TiO}_{2}$ от концентрации $C=f\left(T_{\mathrm{B}}\right), T_{\mathrm{B} 1}=415 \mathrm{~K}, T_{\mathrm{B} 2}=375 \mathrm{~K}$, $T_{\mathrm{B} 3}=340 \mathrm{~K}, T_{\mathrm{B} 4}=330 \mathrm{~K}$

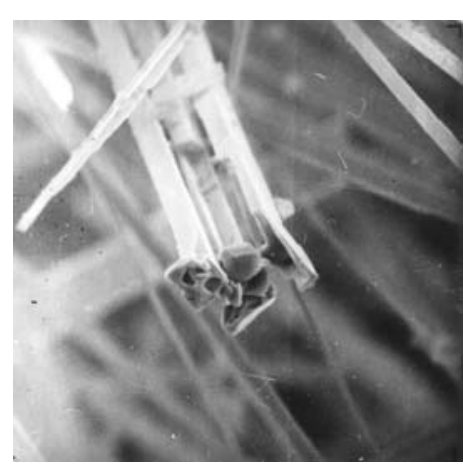

$a$

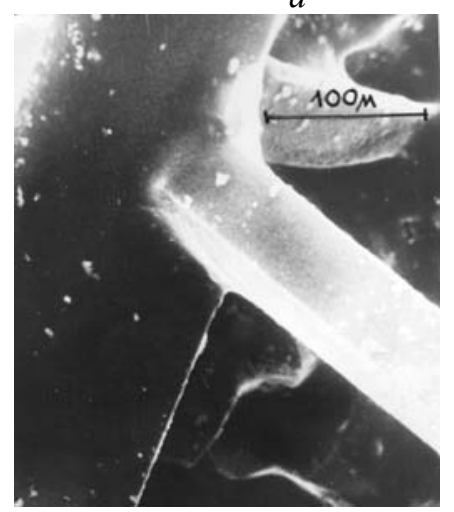

2

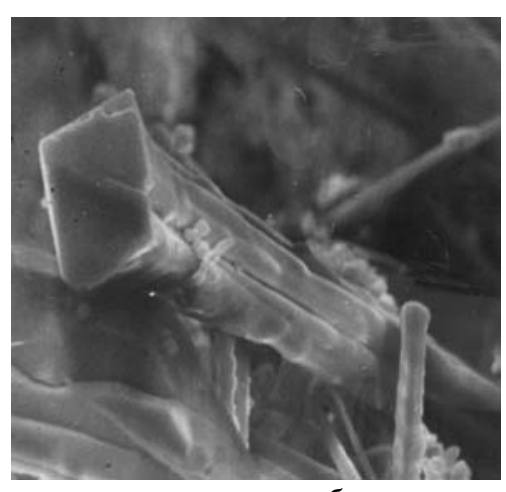

6

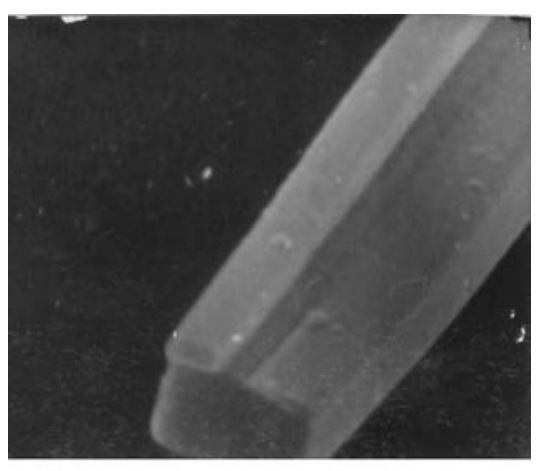

$\partial$
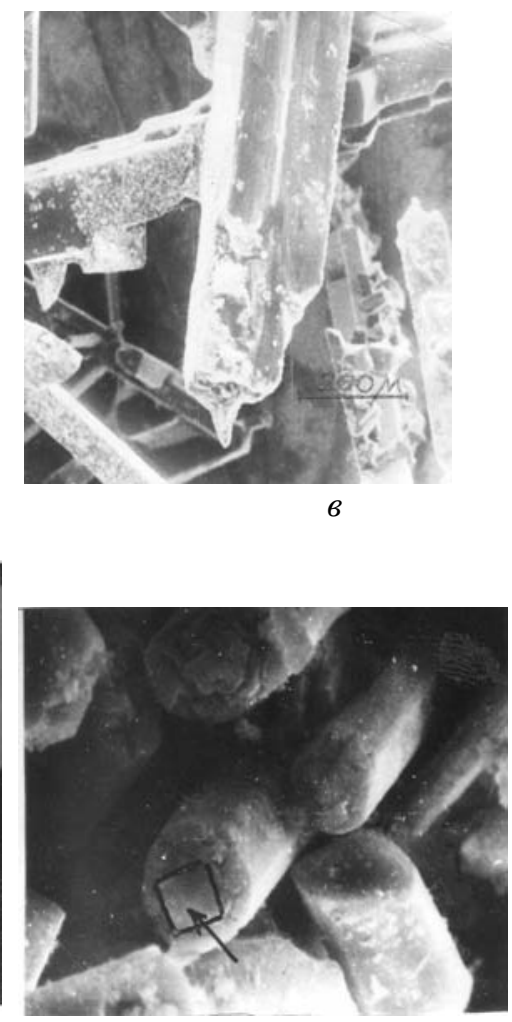

Рис. 7. Ростовые формы нитевидных кристаллов $\mathrm{TiO}_{2}: a, \sigma$ - ассиметричный рост (увеличение в

1000 раз); в, 2- монокристаллы с прямоугольной огранкой (увеличение в 1000 раз); $\partial$ - шероховатые грани кристаллов (увеличение в 10000 раз); $e$ - рост в поперечном сечении (увеличение в 1000 раз) 
Экспозиции (рис. 7, а, б) получены наблююдением за движением включения (рис. 2, а) при толщине расплава 5 и 20 мм, во всех случаях нитевидные кристаллы $\mathrm{TiO}_{2}$ представлены модификациией - рутил. Анализ приведенных данных показывает, что кристаллы растут ассиметрично в плоскости $h k L$ [001] и представляют собой блоки из тончайших монокристальных фибрилл (d=0,005-0,01 мкм), спаянных между собой. С увеличением времени обработки реакционной смесью кристаллы несколько утолщаются за счет неинтенсивного роста в плоскости $h k L[100,011]$ и представляют собой монокристаллы с прямоугольной огранкой (рис. 7, в, г). Для этого периода соотношение скоростей роста в плоскости $h k L$ [001] $v_{e}$ к интенсивности роста $v_{d}$ в плоскостях $h k L[100,011]$ для $\Delta T=5-30$ градусов составляло $v_{e} / v_{d} \cong 300$.

После достижения величины $Y_{\mathrm{c}}^{0}$ (рис. 7, д) боковые грани кристаллов становятся шероховатыми, кристалл интенсивно растет в поперечном сечении (рис. 7, e) и процесс роста прекращается из-за образования сплошной корки на поверхности расплава. Образование корки препятствует диффузии смеси $\left(\mathrm{TiCl}_{4}+\right.$ воздух $)$ в расплав и таким образом источник поступления $\mathrm{TiO}_{2 \mathrm{p}}$ исчезает.

Анализируя приведенные результаты можно записать заключение, основываясь также на [3], что кинетика нормального роста кристалла в рассмотренных случаях (рис. 2, $a ; 7, a-2$ ) может быть описана уравнением:

$$
\frac{d v_{e}}{d \tau}=\frac{w}{w_{1}} D \frac{\partial C}{\partial T} \nabla T
$$

где $D, w_{1}-$ коэффициент диффузии и атомный объем жидкой фазы (расплава $\mathrm{NaCl}, \mathrm{KCl}$ ); $w$ - атомный объем твердой фазы $\left(\mathrm{TiO}_{2}\right) ; C-$ концентрация смеси $\left(\mathrm{TiCl}_{4}+\right.$ воздух $)$ над поверхностью расплава; $\nabla T-$ направление температурного поля по высоте расплава лодочки.

Очевидно, что при константе $C$, что как показано ранее достигается значение $V_{m}$, скорость $v_{e}$ будет зависить от величины $\Delta T$ и величны включения (рис. 2, a). На рис. 8 приведены экспериментальные зависимости $v_{e}$ от размера включения $Y$.

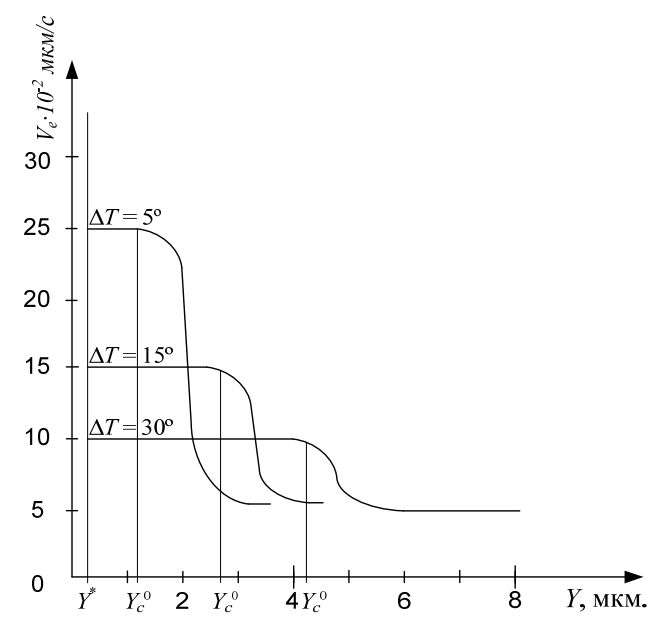

Рис. 8. Зависимость скорости нормального роста нитевидных кристаллов $\mathrm{TiO}_{2}$ от $Y$ в поле $\nabla T$
Как следует из рис. 8 рост кристалла начинается с некоторого критического размера включения $\left(Y^{*}\right)$ независимо от $\Delta T$ и в интервале $Y^{*} \rightarrow$ $Y_{\mathrm{c}}^{0}$ скорость роста $v_{e}$ не зависит от значения размера включения. Это означает, что согласно [3] осуществляется диффузионный рост кристалла со скоростью $v_{e}$. В этом интервале $(Y)$ оценка энергии активации роста дала значение $E_{D e}=17$ ккал/моль, а значение $D_{e} \approx 0,4136 \cdot 10^{-5} \mathrm{~cm}^{2} / \mathrm{c}$.

\section{7. Выводы}

Таким образом, представленные в статье экспериментальные и теоретические результаты открывают возможность практического получения нитевидных кристаллов $\mathrm{TiO}_{2}$ путем окисления $\mathrm{TiCl}_{4}$ кислородом воздуха в расплаве солей $\mathrm{NaCl}, \mathrm{KCl}$. Рассчитанные кинетические параметры позволяют организовать процесс с заданной скоростью протекания и необходимым выходом продукта. Кроме того, приведенные результаты позволяют осознанно подойти к разработке реактора непрерывного или полупериодического действия для производства нитевидных кристаллов $\mathrm{TiO}_{2}$, чему и будут посвящены наши дальнейшие исследования.

\section{Литература}

1. Toyama, S. The production of ultrafine particles by vapor phase oxdization from chloride [Text] / S. Toyama, M. Nakamura, H. Mori, K. Kanai, T. Nachi // Proceedings of the world congress particle technology. - Kyoto, 1990. - P. 360-367.

2. Patent of United Kingdom № 861802-A. Fibrous titanium dioxide and its production [Text] / Application number GB19590020479 1959.06.15, application date: June 15, 1959, publication date: February 22, 1961.

3. Шапорев, В. П. Технологія неорганічних армуючих наповнювачів [Текст]: дис. ... д-ра техн. наук: 05.17.08 / В. П. Шапорев. - Харківський державний політехнічний інститут. Харків, 1995 - 365 с.

4. Dong Jang, H. The effects of temperature on particle size in the gas-phase production of $\mathrm{TiO}_{2}[\mathrm{Text}] / \mathrm{H}$. Dong Jang, J. Jeong // Aerosol Science and Technology. - 1995. - Vol. 23, Issue 4. P. 553-560. doi: 10.1080/02786829508965337

5. Suyama, $\mathrm{Y} . \mathrm{TiO}_{2}$ produced by vapor-phase oxygenolysis of $\mathrm{TiCl}_{4}$ [Text] / Y. Suyama, A. Kato // J. Am Ceram Soc. 1976. - Vol. 59, Issue 3-4. - P. 146-149. doi: 10.1111/j.11512916.1976.tb09453.x

6. Kobata, A. Growth and transformation of $\mathrm{TiO} 2$ crystallites in aerosol reactor [Text] / Kobata, A., Kusakabe, I., and Morooka, S. // AIChE J. - 1991. - Vol. 37, Issue 3. - P. 347-359. doi: 10.1002/aic.690370305

7. Akhtar, M. K. Vapor synthesis of titania powder by titanium tetrachloride oxidation [Text] / M. K. Akhtar, Y. Xiong, S. E. Pratsinis // AIChE J. - 1991. - Vol. 37, Issue 10. P. 1561-1570. doi: 10.1002/aic.690371013

8. Nakaso, K. Effect of reaction temperature on CVD-made $\mathrm{TiO}_{2}$ primary particle diameter [Text] / K. Nakaso, K. Okuyama, M. Shimada, S. E. Pratsinis // Chemical Engineering Science. 2003. - Vol. 58, Issue 15. - P. 3327-3335. doi: 10.1016/s00092509(03)00213-6

9. Drago, R. S. Physical methods in chemistry [Text] / R. S. Drago. -Philadelphia: Saunders, 1977. -660 p.

10. Горелик, С. С. Рентгенографический и электрографический анализ [Текст] / С. С. Горелик, Л. Н. Расторгуев, Ю. А. Скаков. - М.: Металлургия, 1970. - 365 с.

11. Шапорев, В. П. Физико-химические свойства нитевидных кристаллов $\mathrm{K}_{2} \mathrm{Ti}_{6} \mathrm{O}_{13}$, синтезированных разными методами [Текст] / В. П. Шапорев // Изд. АН СССР. - 1992. T. 28, № 8. - C. 1045-1052. 
12. Кафаров, В. В. Основы массопередачи [Текст] / В. В. Кафаров. - М.: Высшая школа, 1962. - 655 с.

13. Франк-Каменецкий, Д. А. Диффузия и теплопередача в химической кинетике [Текст] / Д. А. Франк-Каменецкий. - М.: Наука, 1967. - 490 с.

14. Боресков, Г. К. Катализ [Текст] / Г. К. Боресков. - Новосибирск: Наука, 1971. - 267 с.

15. Эммануэль, Н. М. Курс химической кинетики [Текст] / Н. М. Эмануэль, Д. Г. Кнорре. - М.: Высш. школа, 1974. $-400 \mathrm{c}$.

\section{References}

1. Toyama, S., Nakamura, M., Mori, H., Kanai, K., and Nachi, T. (1990). Proc. World Cong. Particle Tech., Kyoto, Japan, 360-367.

2. Patent UK № 861802-A. Fibrous titanium dioxide and its production. Application number GB19590020479 1959.06.15, application date: June 15, 1959, publication date: February 22, 1961.

3. Shaporev, V. P. (1994). Technology of inorganic reinforcing fillers. Kharkov state polytechnic institute, Kharkiv, Ukraine, 365.

4. Hee, D. J., Jinki, J. (1995). The Effects of Temperature on Particle Size in the Gas-Phase Production of $\mathrm{TiO}_{2}$, Aerosol Science and Technology, 23 (4), 553-560. doi: 10.1080/02786829508965337

5. Suyama, Y., Kato, A. (1976). $\mathrm{TiO}_{2}$ produced by vaporphase oxygenolysis of $\mathrm{TiCl}_{4}$. J Am Ceram Soc., 59(3-4):146-149. doi: 10.1111/j.1151-2916.1976.tb09453.x
6. Kobata, A., Kusakabe, I., Morooka, S. (1991). Growth and transformation of $\mathrm{TiO} 2$ crystallites in aerosol reactor. AIChE, 37 (3), 347-359. doi: 10.1002/aic.690370305

7. Akhtar, M. K., Xiong, Y., Pratsinis, S. E. (1991). AIChE, 37 (10), 1561-1570. doi: 10.1002/aic.690371013

8. Nakaso, K., Okuyama, K., Shimada, M., Pratsinis, S. E. (2003). Effect of reaction temperature on CVD-made $\mathrm{TiO}_{2}$ primary particle diameter. Chemical Engineering Science, 58 (15), 3327-3335 doi: 10.1016/s0009-2509(03)00213-6

9. Drago, R. S. (1977). Physical methods in chemistry, Philadelphia: Saunders, 660.

10. Gorelik, S. S., Rastorguyev, L. N., Skakov, Yu. A. (1970). Sciagraphy and electrosensitive analysis. Moscow, USSR: Metallurgy, 365.

11. Shaporev, V. P. (1992). Physical and chemical properties of threadlike crystals $\mathrm{K}_{2} \mathrm{Ti}_{6} \mathrm{O}_{13}$, synthesized by different methods, Izd. AS USSR. 28 (8), 1045-1052.

12. Kafarov, V. V. (1962). Bases of mass transmissions massoperedachy Moscow, USSR: High school Publishing House, 655.

13. Frank-Kamenetskiy, D. A. (1967). Diffusion and heattransfer in chemical kinetics. Moscow, USSR: Nauka Publishing House, 490.

14. Boreskov, G. K. (1971). Catalysis. Novosibirsk, USSR: Nauka Publishing House, 267.

15. Emanuel, N. M., Knorre, D. G. (1974). Course of chemical kinetics. Moscow, USSR: High school Publishing House, 400.

Дата надходження рукопису 17.10.2014

Шапорев Валерий Павлович, доктор технических наук, профессор. кафедра химической техники и промышленной экологии, Национальный технический университет «Харьковский политехнический институт», ул. Фрунзе, 21, г. Харьков, Украина, 61002

E-mail: fiola2008@mail.ru

Шестопалов Алексей Валерьевич, кандидат технических наук, доцент, кафедра химической техники и промышленной экологии, Национальный технический университет «Харьковский политехнический институт», ул. Фрунзе, 21, г. Харьков, Украина, 61002

E-mail: pheonix_alex@mail.ru

Питак Инна Вячеславовна, кандидат технических наук, доцент, кафедра химической техники и промышленной экологии, Национальный технический университет «Харьковский политехнический институт», ул. Фрунзе, 21, г. Харьков, Украина, 61002

E-mail: ipitak5@gmail.com

УДК 681.324

DOI: $10.15587 / 2313-8416.2014 .28685$

\section{МЕТОДИ УСУНЕННЯ ІНТЕГРАЛЬНОГО НАСИЧЕННЯ В СИСТЕМАХ АВТОМАТИЧНОГО РЕГУЛЮВАННЯ 3 ПІД-РЕГУЛЯТОРАМИ}

\section{() Д. О. Кроніковський}

При використанні класичних ПІД-регуляторів в реальних об'єктах виникає ефект інтегрального насичення, щуо негативно впливає на якість процесу регулювання.

Було розглянуто жомосушарку иукрового заводу, як реальний об'єкт автоматизації. На основі моделювання прочесів керування в жомосушариі було продемонстровано вплив інтегрального насичення. Розглянуто використання сучасних підходів для усунення иьього ефекту.

Ключові слова: інтегральне насичення, ПІД-регулятори, жомосушарка, час регулювання, якість регулювання.

The effect of integral saturation that reduces the quality of regulation appears with classic PID-controller usage in the real conditions. 